\title{
Planar Inter Digital Capacitive Sensor for Real time Transesterification Progress Monitoring of Karanja (Pongamia) Oil
}

\author{
Krishnamurthy Bhat ${ }^{1}$, Bharati S. Meti ${ }^{2}$, K. Chandrasekhar ${ }^{3}$ \\ ${ }^{1}$ Department of Electronics and Instrumentation Engineering, Basaveshwar Engineering College, Bagalkot, Karnataka, India \\ ${ }^{2}$ Department of Bio-Technology, Basaveshwar Engineering College, Bagalkot, Karnataka, India \\ ${ }^{3}$ Department of Physics, Basaveshwar Engineering College, Bagalkot, Karnataka, India

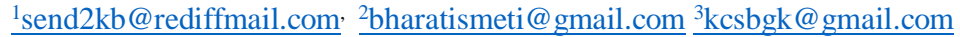

\begin{abstract}
Transesterification is a well known chemical process of producing biodiesel from edible and non-edible oils, animal fats and cooked oils. Base catalytic transesterification of non-edible oil is a popular method for production of biodiesel. Biodiesel production from Karanja or Honge (Pongamia pinnata) seed oil is gaining momentum in India and other parts of world. The real time monitoring of transesterification reaction progress is essential step towards automating biodiesel production. Two planar inter digital capacitive sensors (IDCS) are fabricated for the purpose of monitoring the transesterification progress of Karanja oil and their performance are evaluated. The repeatability and sensitivity of fabricated sensor is reliable and acceptable. The sensor with associated signal conditioning circuit will be useful in automating the biodiesel production process and play vital role in energy efficiency and the quality of end products.
\end{abstract}

Keywords- Inter digital capacitive sensor, Transesterification progress, Karanja oil, Pongamia pinnata, Biodiesel process monitoring

\section{Introduction}

Efficient generation, distribution, and effective conservation of renewable energy are of immediate need. It is expected that the global per capita energy demand will peak before 2030 [1]. Renewable energy is the fastest growing source of energy at $7.1 \%$ per annum and it accounts for $40 \%$ of the growth in power generation, causing their share of global power to increase from $7 \%$ in 2015 to nearly $20 \%$ by 2035 [2]. Biofuels (Ethanol and biodiesel) are the bioenergy in liquid form. Biodiesel production from non edible seed oils is gaining momentum due to inherent multiple advantages. Large numbers of non edible seed oils are tried for biodiesel production [3]. Several government and private organizations are set up in India to promote continuous research and development in biodiesel sector [4]. National Biofuel Policy of India encourages the production of biodiesel and targets for $20 \%$ blending [5]. Pongamia oil is widely used for biodiesel production and it is a potential alternative to conventional diesel engine fuels. It has high flash point and high calorific value [6]. Pongamia pinnata or Karanja or Honge is an ever green fast growing tree found almost everywhere in India and many other countries which can produce non edible oil seeds of 135000 million tonnes per annum. However, only $6 \%$ of Karanja produce is being utilized [7]. Air-dried Pongamia kernels have 27.5\% - 30\% fatty oil. Most common method of biodiesel production from non edible seed oil is through alkaline catalytic transesterification reaction. The conversion is quite slow at the start, picks up rapidly up to first 10-15 minutes and reaches steady state in a time of one hour or more. A typical reaction rate is discussed by Demirbas A. [8]. Transesterification reaction is reversible and hence, excess alcohol is used to shift the equilibrium to the product side [9].

\section{Existing monitoring methods for biodiesel production} process

Several research works are carried around the world to achieve energy and cost efficiency in biodiesel production. Chromatography and spectroscopy are the two powerful analytical tools frequently used for accurate and detailed analysis of biodiesel. Varieties of process monitoring methods are proposed. GC is applied by many researchers to study transesterification. The characteristics of transesterification of soybean oil were studied using GC by Freedman et al. [10] and Plank et al. [11]. Use of Gel Permeation Chromatography (GPC) for palm oil transesterification is reported by Darnoko [12]. NIR and Nuclear Magnetic Resonance (NMR) spectroscopic methods are used to find the blend level of mixtures of biodiesel with conventional petro diesel fuel [13]. Batch reactor type biodiesels are more attractive because of low cost and suitable to locality. Biodiesel conversion in such reactors needs to be monitored to increase the efficiency. Other methods used for online monitoring use changes in physical parameters of reactants such as viscosity, dispersion of bubbles, change in color, and $\mathrm{pH}$ value. Felizardo $e$ al. have used NIR spectroscopy based fiber-optic probe to quantify the content of water and methanol in biodiesel [14-15]. Yield and quality of biodiesel extracted from soybean oil is assessed using Raman spectroscopy by Ghesti et al. [16]. 
Viscometric method is employed by Ellis et.al. to monitor the viscosity changes during the reaction due to change in shear stress of reactants [17]. Change in density of reactant is also used in some cases [18]. Long-period grating (LPG) fiber optic sensor which measures the change in refractive index of surrounding media is also used by Falate et al. with an error in the detection of as low as $0.4 \%$ [19]. There are reports of use of laser spectroscopy employing a laser source of 650nm with Light Dependent Resistor (LDR) as detector for monitoring the transesterification process of soybean oil [20]. Clark et al. described the method of using $\mathrm{pH}$ for this purpose [21]. Microwave technique is relatively new method and in one of its form [22]. Each method has its some merits and demerits compared to others. However, they are unsuitable for low cost industrial process monitoring and control purposes because of various reasons such as requirement of intensive sample preparation or high cost of the equipment or sluggish response. Further, these methods also prompt the possibility of employing sensors for feedback control purposes. Optimization of the biodiesel trans-esterification process is possible by on line monitoring of process steady state conditions. This will help to save energy during the process by reducing mechanical agitation or by reduction of heat energy input [23]. Small scale and pilot type biodiesel plants are very much required to encourage local farmers to grow more non edible seed plants in arid and non-agricultural lands. There are suggestions of process optimization using mixing techniques, novel heating, and net energy scenarios for different feedstocks. Energy intensive process steps involved in the production of biodiesel is the main reason for non sustainability [24]. Most of small scale production plants are batch reactor based and need lots of automation in several aspects to avoid human operator's monitoring and intelligence. Several automation possibilities are identified and discussed for biodiesel plants. On line monitoring of transesterification progress and determination of process steady state conditions are important part of automation [25]. An economically viable and technically suitable sensor and associated instrumentation for the said purpose is required [26]. Transesterification progress monitoring is an important aspect of biodiesel production.

\section{Capacitive sensor for transesterification reaction progress monitoring}

Capacitive sensors are simple in construction and cost effective. Though capacitive sensors find large number of applications for the detection of various physical, physiological and electro-chemical parameters, very few reports of employing capacitive sensors for transesterification progress monitoring in biodiesel production process are available. In an effort to improve the biodiesel production performance, a non invasive measurement method involving electrical capacitance tomography system is developed by Syed F. A. Bukhari et al. [27]. Inter digital capacitive probe for monitoring of biodiesel transesterification process of sunflower oil is reported by Tri Rachmanto. The work is more concentrated on temperature and frequency effect on impedance. A work employing GC-MS and dielectric sensors for characterization of biodiesel fatty acid content is also reported [28]. The structure of material and the chemical reaction mechanism for biodiesel process using impedance spectroscopy with high frequency sweeps was carried out by Cho [29]. The study has shown that changes in dielectric properties can be used in a simple method for monitoring biodiesel operations. Corach et al. [30] reported that permittivity values obtained from impedance measurement technique can be used to determine the quality of biodiesel product. Similar method is employed by Romano and Sorichetti, for evaluation of electric characteristic of biodiesel during transesterification of waste frying oils. The conductivity and dielectric properties of the reactants were measured in the range frequency $100 \mathrm{~Hz}$ to $15.7 \mathrm{kHz}$. Different stages biodiesel production from raw material to the final product can be controlled by the method of monitoring the physico-chemical and electrical properties [31-32]. Karanja oil is extracted from its seeds and biodiesel is produced using alkali catalytic transesterification process. The oil is heated to $40-60^{\circ} \mathrm{C}$ temperature and added with a proportional quantity of methanol and sodium (potassium) hydroxide, mixed thoroughly for more than an hour to obtain biodiesel and glycerin. Planar inter digital capacitive sensor (IDCS) is a low cost solution for monitoring the base catalytic transesterification reaction of Karanja oil.

\section{A. Electrical impedance analysis of capacitive sensors}

The variation in impedance of a capacitive sensor is possible by the variation in the dielectric property of the material. During transesterification, reaction kinematics will result into variation in dielectric property of the reactants. Summarizing the analysis reported in literature [31-35], the apparent relative permittivity of the sample at an angular frequency $\omega$ can be considered as consisting of $\varepsilon_{r}^{\prime}(\omega)$, related to the storage of electrostatic energy due to electric polarization and $\varepsilon_{r p o l}^{\prime \prime}(\omega)$ the imaginary part owing to the dissipation of energy associated with relaxation process of dielectric polarization in the sample. Hence, the relative permittivity is written as:

$$
\varepsilon_{r}(\omega, T)=\varepsilon_{r}^{\prime}(\omega, T)-\varepsilon_{r p o l}^{\prime \prime}(\omega, T)-i \frac{\sigma(T)}{\varepsilon_{o} \omega}
$$

$\varepsilon_{\text {rpol }}^{\prime \prime}$ has a value appreciably different from zero, only in the range of frequencies around the inverse of the characteristic time of the relaxation process. Third term is related to the dissipation due to charge transport 
phenomena. When $(\omega \rightarrow 0)$ i.e. at low frequencies it dominates the imaginary part of the complex permittivity.

In the work carried by J. Corach et al. [30, 34] much simpler relationship is presented and the relative permittivity is modeled as:

$$
\varepsilon_{r}(\omega, T)=\varepsilon_{r}^{\prime}(T)-i \frac{\sigma(T)}{\varepsilon_{o} \omega}
$$

Due to the fact that thermal agitation tends to oppose to the polarization, $\varepsilon_{r}^{\prime}(\omega)$ usually decreases with increase in the temperature.

Further, $\varepsilon_{r}^{\prime}(T)$ can be written as:

$$
\varepsilon_{r}^{\prime}(T)=\varepsilon_{r}^{\prime}\left(T_{o}\right)+\frac{d \varepsilon_{r}^{\prime}}{d t}\left(T-T_{o}\right)
$$

Here, $\varepsilon_{r}^{\prime}\left(T_{o}\right)$ is the fitted value at some reference temperature $T_{0}$ and $\frac{d \varepsilon_{r}^{\prime}}{d t}$ is the rate of change of $\varepsilon_{r}^{\prime}$ with temperature. The value of $\frac{d \varepsilon_{r}^{\prime}}{d t}$ may be assumed constant in the range of usual temperature for biodiesel process. The conductivity $\sigma(T)$ of sample increases rapidly with temperature and given by:

$$
\sigma(T)=\sigma \exp \left(\frac{d}{T}\right)
$$

Equations (1) to (4) show that the capacitance variation is due to dielectric permittivity variation of sample. Summarizing the above analysis, the relative permittivity $\varepsilon_{r}(\omega, T)$ of a sample liquid depends on the electric polarization and dissipation of electric energy due to relaxation process of dielectric polarization. $\varepsilon_{r}(\omega, T)$ has dependency on both frequency of excitation and temperature. Measurement of permittivity and conductivity (admittance) can be employed for the application of on line measurements during transesterification reaction in biodiesel production process and systems. The relative permittivity or dielectric property of reaction mixture is the key factor when the transesterification progress is to be monitored by capacitive sensors. Karanja oil exhibits a good dielectric property and Analysis and experimentations carried by T. Mariprasath et al. [35] reveal that the viscosity of Karanja oil is low compared to soybean, coconut and sunflower oil and tits average dielectric breakdown strength is very high. The moisture content also reduces when stored. The dielectric dissipation factor of the oil samples has increased with aging. The dielectric constant of Karanja oil is higher than that of mineral oil. Karanja oil has higher resistivity which implies that contamination rate is very low. The dielectric constant (relative permittivity) of the oil is fairly constant with its age up to 60 days from its fresh extraction and it ranges from 4.0 to 4.2. The specific resistivity $(\Omega \mathrm{m})$ is very high in the same age period and it is $1.2 \times 10^{14} \Omega$ [36]. Quite large numbers of applications employing IDC are reported in literature. IDC sensors are used for bio-impedance detection/measurement of biological contaminants and poisons in sea foods, moisture content paper, pulp and woods, quality estimation in dairy and leather products, natural water analysis [37]. An IDC sensor of spatial periodicity of $40 \mathrm{~mm}$, each finger length of $160 \mathrm{~mm}$ and effective penetration depth of $7 \mathrm{~mm}$ is designed and used by K. Sundara-Rajan et al. [38-39]. ID based sensors using electromagnetic principle are also used for detection and inspection of both conducting and non-conducting surfaces and cavities [40]. An IDC sensor with nine sensing electrodes of which three are active electrodes was designed and tested for water content in paper [41]. Inter digital capacitive sensors are also designed for several other specific applications. In one of the application an IDC was designed and used for fat content estimation in fork meat [42]. Dielectric based IDC sensors are designed for the purpose of detection and discrimination of contaminants and poisons in sea food such as mussels [43]. Coplanar IDC sensor with different sweep frequency was tested for glucose dilution measurement [44]. A flexible planar inter digital sensor in sweep frequency band of $1-15 \mathrm{GHz}$ was for detection of water contaminants [45]. The research work carried by show that the dielectric property of reaction mixtures of methanol, ethanol, glycerin and some vegetable oils during transesterification is both temperature and frequency depended [46]. Because of several advantages like low cost, ease of fabrication, reliable and acceptable measurement accuracy and sensitivity they are preferred for many applications.

\section{IDC Sensor fabrication details}

A uniform plate of $16 \mathrm{~mm}$ width and $110 \mathrm{~mm}$ length is cut from a glass epoxy substrate copper clad sheet using shear cutting machine. The required size and pattern of inter digits or fingers are generated in Adobe Photoshop. The pattern is transferred and printed with ink jet on the copper side of the clad. Etching is done using Ferric chloride solution at normal speed. After etching board surface is cleaned and dried before using it. Two IDC sensors (IDCS-1, IDCS-2) are fabricated with 10 and 9 numbers of alternately excited fingers (digits). Snap shots of the two sensors are given in Fig. 1. 
Fig. 1

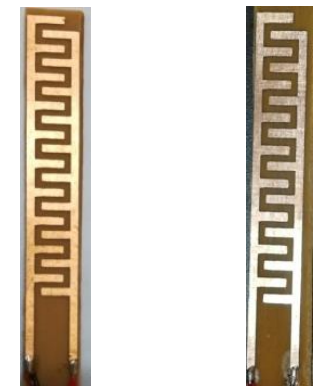

\section{Experimentation on IDC sensors}

Oil extracted from Pongamia pinnata (Honge or Karanja) seed is used for all the experiments. The oil is double filtered and pre-heated to remove most of the impurities and moisture. Hence, the composition of this oil is $100 \%$ of Karanja oil. Laboratory grade methanol and dried flakes of sodium hydroxide $(\mathrm{NaOH})$ are also used. All the materials are supplied by Bioenergy Research, Information, and Demonstration Centre (BRIDC), Bagalkot. 1:6 molar ratio of oil to methanol is used to ensure complete conversion. The experimental set up is given in Fig. 2.

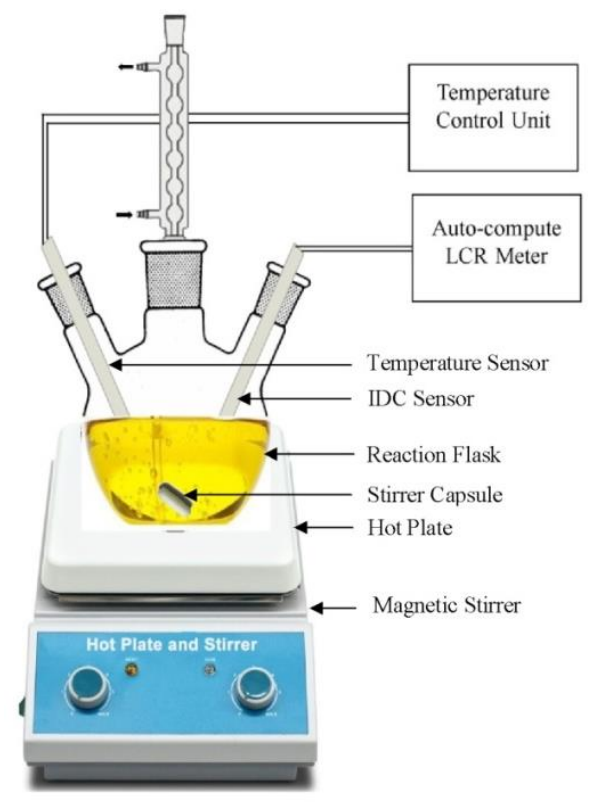

Fig. 2

\section{A. Procedure}

7.0 grams of $\mathrm{NaOH}$ flakes are mixed with $300 \mathrm{ml}$ of methanol. One liter of Karanja oil is taken in a 2 liter capacity three neck flask with magnetic capsule. A temperature sensor and IDC capacitive sensor are dipped into the oil. A water condenser is also used to minimize vaporization. Temperature sensor is connected to the controller circuit to control the hot plate. The capacitive sensor is connected to an auto-computing LCR meter of APLAB Make Model No. 4910. The stirring speed of 800 $\mathrm{rpm}$ is maintained. Oil is heated to $60^{\circ} \mathrm{C}$ and preheated methoxide is gently mixed with oil. The capacitance value of the sensor is monitored on the LCR meter and recorded for every regular interval.

\section{B. Sensor equivalent circuit and analysis}

Coplanar inter digital capacitive sensor consists of repetitive electrodes in definite fashion. In an application the electrodes are supplied by an AC sinusoidal voltage of fixed magnitude. This creates electric field in the material to which it is exposed.

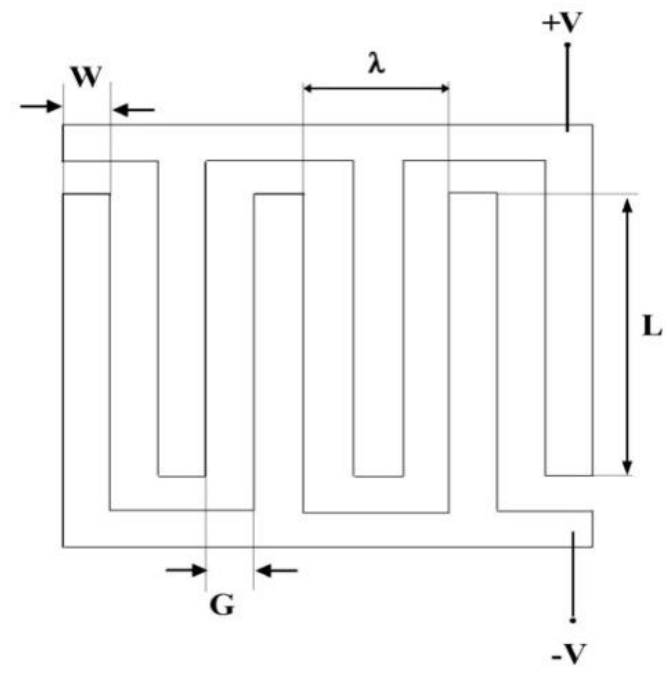

Fig. 3

The magnitude of impedance of IDC sensor can be expressed as:

$$
|Z|=\sqrt{R^{2}+X^{2}}
$$

In equation $5, X$ represents both capacitive and inductive reactance. Since inductive impedance is negligibly small it is ignored in all practical applications.

Hence, the impedance becomes:

$$
|Z|=\sqrt{R^{2}+\left(-\frac{1}{2 \pi f C}\right)^{2}}
$$

From equation 6, it is clear that the impedance of IDC sensor depends on resistance, capacitance and excitation frequency. If the frequency of excitation source is fixed, the impedance depends on capacitance value.

IDC sensor was analyzed and more exact expression for its capacitance is developed by Igreja et al [47]. The expression can be used for computing the capacitance value of IDC sensor. The technique of calculating capacitance proposed in this work uses conformal mapping. The IDC sensor consisting of two inter-penetrating comb electrodes with gap $(G)$, each finger width $(W)$, common finger length $(L)$ is shown in Fig. 3. The capacitance of IDC changes only due to the property of material over the surface 
(sensitive layer) of it. When the capacitor electrodes are supplied by constant voltages $+\mathrm{V}$ and $-\mathrm{V}$, the equipotential lines are as depicted in Fig. 4.

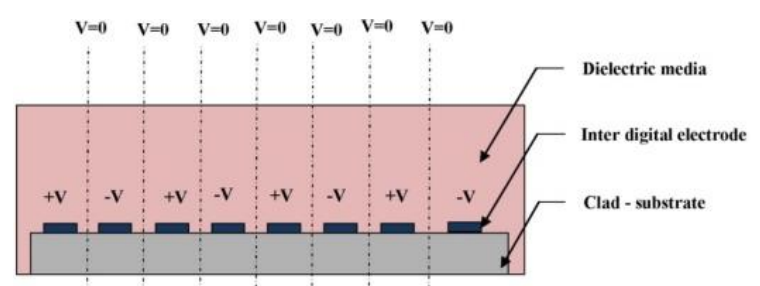

Fig. 4

The dimensional factor $\eta$ called metallization ratio for the sensor is defined by equation 7 as:

$$
\eta=\frac{W}{W+G}=\frac{2 W}{\lambda}
$$

Where,

$(\lambda=2(\mathrm{~W}+\mathrm{G}))$ is called special wavelength of sensor. Considering the IDC sensor consisting of repeating set of capacitors and resistors, its equivalent circuit is drawn in Fig. 5.

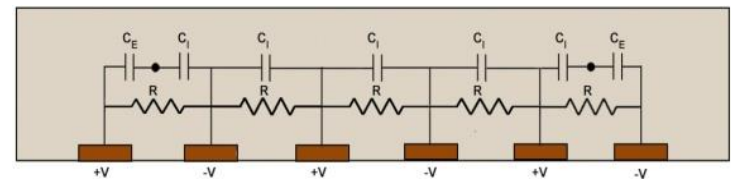

Fig. 5

If the number of electrodes $\mathrm{N}>3$ (in this work $\mathrm{N}=10$ ), the equivalent capacitance of the sensor is given by equation 8.

$$
C_{S}=(N-3) \frac{C_{I}}{2}+2 \frac{C_{I} C_{E}}{C_{I}+C_{E}}, N>3
$$

Where $C_{S}$ is the sensor capacitance, $C_{I}$ is half the capacitance between an interior electrode and the ground $(\mathrm{V}=0)$ and $C_{E}$ is capacitance of one outer electrode relative to the ground plane next to it.

In most of the applications, coplanar inter digital capacitive sensor is excited by a constant AC excitation from a stable source with an external series resistor R as shown in Fig. 6.

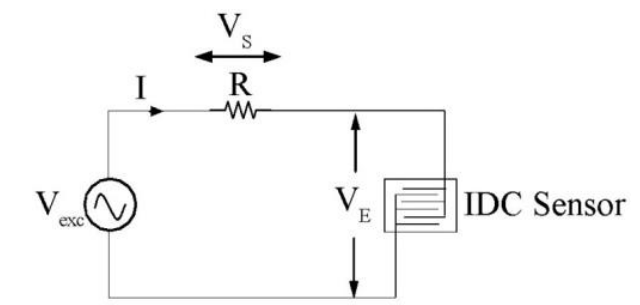

Fig. 6

The impedance of capacitive sensor responds to the dielectric changes in the media where it is exposed. Phase angle between current and voltage as well as magnitude of voltage developed across the capacitor and resistor are measured to find the impedance of sensor. However, a robust automatic computing digital LCR meter is used to measure directly the capacitance of the sensor.

\section{C.Results and discussions}

The transesterification reaction of Karanja oil was monitored using both IDC sensors (IDCS-1 and IDCS-2) separately. Two different samples of Karanja oil were collected from District Biodiesel Centre. Sample-1 was fresh extract from Karanja seeds and sample-2 was Karanja oil stored for more than 15 days.

\section{C1.Response of IDCS-1}

The air capacitance of IDCS-1 was $65.2 \mathrm{pF}$ and when dipped into oil, the capacitance value reached up to $68.8 \mathrm{pF}$.

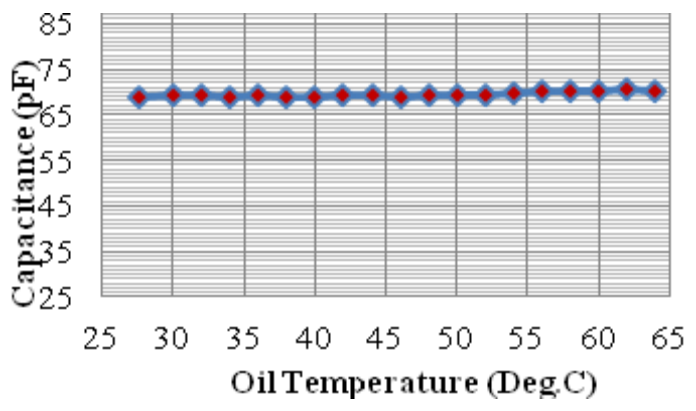

Fig. 7

The change in the capacitance is relatively small and constantly increasing in the range of 25 to $65^{\circ} \mathrm{C}$ as shown in Fig. 7. The overall variation is less than $2.2 \mathrm{pF}$ for the entire range which is negligible compared to the nominal capacitance of sensor.

Figure 8 illustrates the response of IDCS-1 for sample-1 for two trials on a single day. The effect of methoxide on the capacitance in the initial stage was observed here. The capacitance increased sharply in the range of few $\mu \mathrm{F}$, when methoxide was added and decreased to few $\mathrm{nF}$ in rapid time.

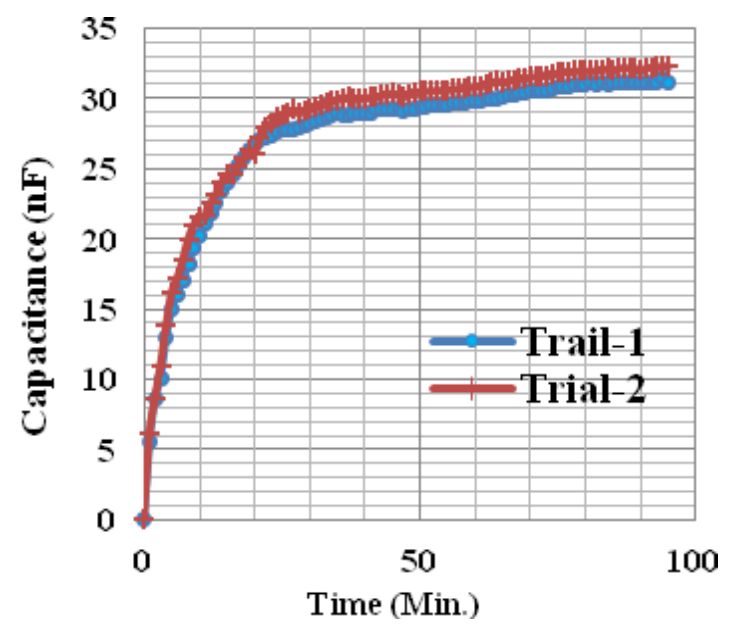

Fig. 8 
In the first 10 minutes, the transesterification reaction is rapid and reaches up to $70 \%$ conversion. The capacitance value reaches to an average value of $31.5 \mathrm{nF}$ in a time period of one hour. The response obtained reveals that the repeatability of IDCS sensor is quite good and promising. The response has reached a plateau with $99 \%$ conversion in an average reaction time of 85-90 minutes. The IDCS - 1 was tested on the second sample of Karanja oil. The fat content of oil has resulted into little more capacitance. However, the contour of response follows that of sample-1 only. The response of IDCS-1 for sample -2 is as shown in Fig. 9.

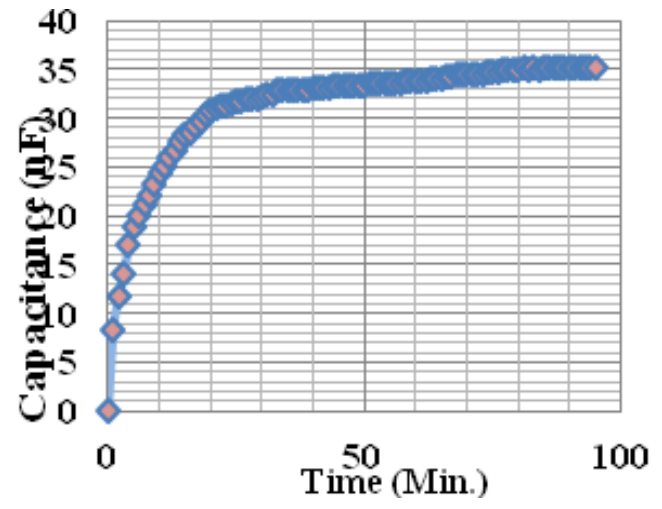

Fig. 9

\section{C2.Response of IDCS-2}

The capacitance of second sensor (IDCS-2) was little less compared to IDCS-1. Air capacitance of IDCS-2 was $61.7 \mathrm{pF}$ including its connecting cable. When it was dipped in oil, the capacitance value has changed to $65.4 \mathrm{pF}$. The rapid change in the capacitance (few $\mu \mathrm{F}$ ) during initial few seconds on mixing the oil with methoxide was noticed in this case also. Fig. 10 gives the temperature response of IDCS-2.

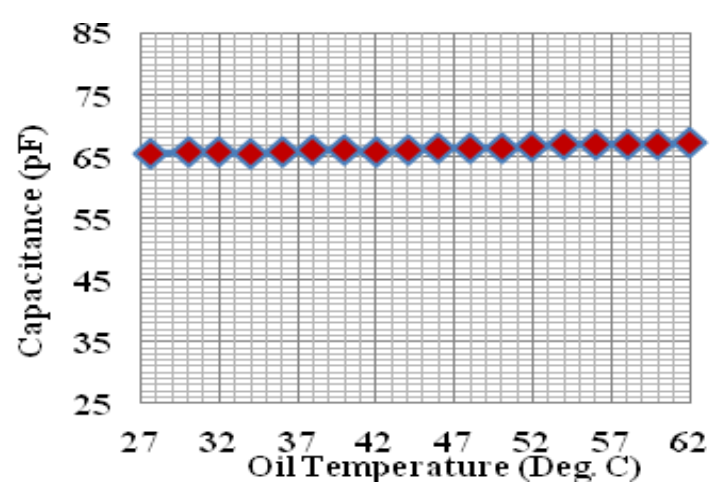

Fig. 10

The temperature effect on the capacitance variation is small and negligible. In most of the batch reactor based biodiesel production, the transesterification reaction temperature is in a small range of $40-60^{\circ} \mathrm{C}$ and hence, practical significance of temperature sensitivity of IDCS is less. The transesterification progress of two different samples of Karanja oil was monitored by IDCS-2 to evaluate its reliability. Variation in the sensor capacitance of IDCS-2 during transesterification of two samples of Karanja oil with methoxide at $60^{\circ} \mathrm{C}$ reaction temperature carried for 95 minutes is depicted in Fig. 11. The maximum capacitance variation for sample -1 and sample- 2 are $33.1 \mathrm{nF}$ and $36.5 \mathrm{nF}$ respectively. The sensor capacitance reaches plateau in almost one hour reaction time where $95 \%$ of conversion was completed.

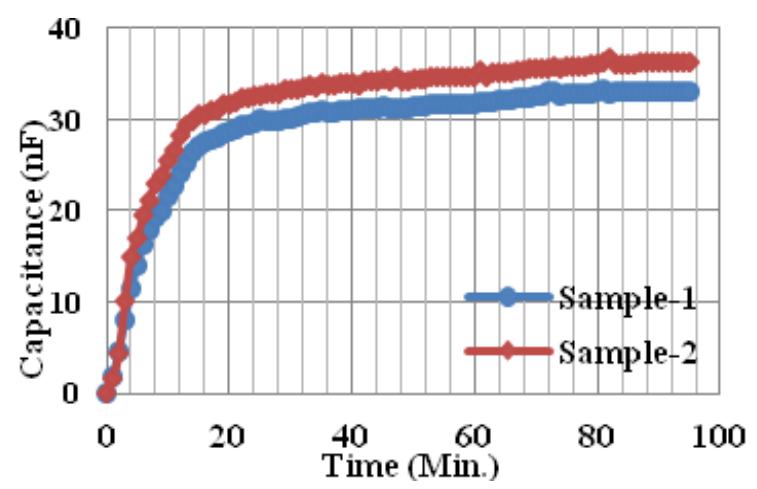

Fig. 11

\section{C3.Analysis of IDC sensor response}

The responses of IDC sensor during transesterification progress presented in the previous section reveal that the change in capacitance is practically detectable and measurable. The complete response of the sensor during the transesterification reaction for 95 minutes duration can be put into five distinct characteristic phases (a, b, c, d, e) as shown in Fig. 12.

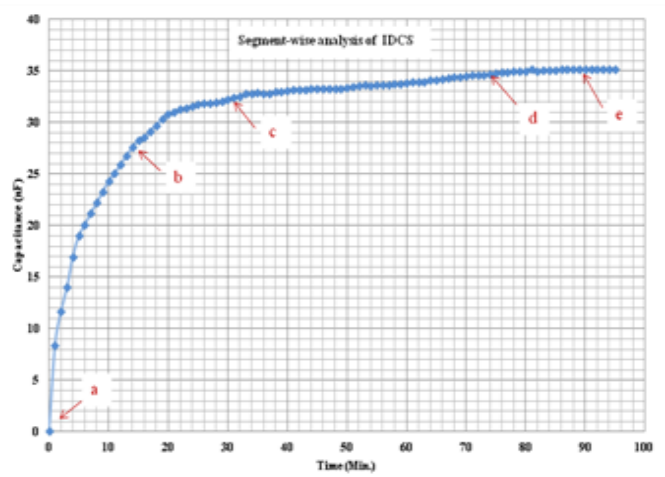

Fig. 12

The capacitance of IDC sensor is very small in few $\mathrm{pF}$ when dipped in Karanja oil at $60^{\circ} \mathrm{C}$ reaction temperature (Marking "a"). On the other hand, capacitance of sensor for methoxide is very large in few $\mu \mathrm{F}$. When the oil is mixed with methoxide, for the first few seconds, the capacitance value shot up as high as up to $10-12 \mu \mathrm{F}$. This is due to the influence of methoxide before it mixes uniformly with oil. However, this mechanism is not the part of transesterification reaction. The capacitance of probe decreases to few $\mathrm{pF}$ when 
the methoxide is mixed with oil. For the first 10 -15 minutes (Segment $a-b$ ) after the thorough mixing of methoxide, the capacitance of sensor increases sharply from $\mathrm{pF}$ to few $\mathrm{nF}$. During this time period, the reaction rate is very fast and it signifies the conversion of most of triglycerides of oil converted into diglyceride, monoglyceride, methyl esters and glycerol.

The conversion of diglyceride and monoglyceride into methyl ester (biodiesel) and glycerol continues in the segment $(b-c)$. It also shows the slow rate of transesterification or conversion as most of diglyceride and monoglyceride are converted at this stage. The state of chemical equilibrium of transesterification reaction almost reaches at " $\mathrm{d}$ " and hence the biodiesel conversion rate in the segment (c-d) is almost stagnant. Point " $d$ " on the response signifies almost $99.9 \%$ of conversion and hence, this point is to be electronically detected from the measured value of capacitance to end the reaction automatically by turning off heater and stirrer. This will ensure the energy efficiency. An electronic method of detection of this point subsequently, turning off the heater and stirrer is possible to ensure the efficiency of transesterification.

\section{Conclusion}

The Karanja seed oil is a potential feedstock for biodiesel production through catalytic transesterification reaction in batch reactor based production plants. Automation of such plants is required in order to reduce the cost of production and gain energy efficiency. Transesterification reaction progress real time monitoring and end product detection is a big step towards automation of biodiesel production process. Capacitive sensors are cost effective and acceptable solution for this purpose. The fabrication and testing of inter digital capacitive sensors (IDCS) for alkali catalytic transesterification reaction progress monitoring of Karanja oil with methanol at $60^{\circ} \mathrm{C}$ reaction temperature are explained in this paper. The responses of sensors are promising and will be useful for further work related to detection of transesterification end point. This will definitely ensure the quality of end product and energy efficiency for biodiesel production from Pongamia (Karanja) oil.

\section{Acknowledgements}

We sincerely thank the authority and staff of Bio-energy Research, Information, and Demonstration Centre (BRIDC), at Basaveshwar Engineering College, Bagalkot, Karnataka, India for extending cooperation and timely help in providing facilities and materials required to carry out this research work.

\section{References}

[1] BP Statistical Review of World Energy, Bob Dudley, British Petroleum, June 2017.

\section{[2] World Energy Scenario 2016, World Energy Council.}

[3] BP Energy Outlook, 2017 Edition, www.bp.com/ energy outlook https://www.bp.com/content/ dam/bp/pdf/ energy-economics/energy-outlook-2017/bp-energy-outlook2017.pdf.

[4] Arvind Lali, "Biofuels for India: what, when and how," published in Current Science, Volume 110, Issue 4, 2016, pp.552-555.

[5] National Policy on Biofuels, Ministry of New and Renewable Energy, Government of India, New Delhi, India http://mnre.gov.in/file-manager/UserFiles/biofuel_policy. pdf.

[6] Gaurav Dwivedi, M.P.Sharma, "Prospects of biodiesel from Pongamia in India," published in Renewable and Sustainable Energy Reviews, Volume 32, 2014, pp.114122.

[7] Bobade S.N., Khyade V.B., "Detail study on the Properties of Pongamia pinnata (Karanja) for the Production of Biofuel," published in Research Journal of Chemical Sciences, Volume 2, Issue 7, 2012, pp. 16-20.

[8] Demirbas A., "Biodiesel fuels from vegetable oils via catalytic and non-catalytic supercritical alcohol transesterification and other methods: a survey," published in Energy Conversion and Management, Volume 44, Issue 13, 2003, pp. 2093-2109.

[9] M.E. Borges, L. Díaz, "Recent developments on heterogeneous catalysts for biodiesel production by oil esterification and transesterification reactions: A review," published in Renewable and Sustainable Energy Reviews, Volume 16, 2012, pp. 2839-2849.

[10] Freedman B., Butterfield R. O., Pryde E. H., "Transesterification kinetics of soybean oil," published in Journal of the American Oil Chemists' Society, Volume 63, Issue 10, 1986, pp. 1375-1380.

[11] Plank C., E. Lorbeer, "Simultaneous determination of glycerol and MG, DG and TG in vegetable oil methyl esters by capillary gas chromatography," published in Journal of Chromatography A, Volume 697, 1995, pp.461-468.

[12] Darnoko D., M. Cheryan, E. G. Perkins, "Analysis of vegetable oil transesterification productions by gel permeation chromatography," published in Journal of Liquid Chromatography and Related Technologies, Volume 23, 2000, pp. 2327-2335.

[13] Knothe G., "Monitoring a progressing transesterification reaction by fiber-optic near infrared 
spectroscopy with correlation to $1 \mathrm{H}$ nuclear magnetic resonance spectroscopy," published in Journal of the American Oil Chemists' Society, Volume 77, Issue 5, 2000, pp. 489-493.

[14] Felizardo P., Baptista P., Menezes J. C., Correia M., "Multivariate near infrared spectroscopy models for predicting methanol and water content in biodiesel," pubished in Analytica chimica acta, Volume 595, Issue 1, 2007, pp. 107-113.

[15] Knothe G., "Determining the blend level of mixtures of biodiesel with conventional diesel fuel by fiber-optic nearinfrared spectroscopy and $1 \mathrm{H}$ nuclear magnetic resonance spectroscopy," published in Journal of the American Oil Chemists' Society, Volume 78, Issue 10, 2001, pp. 10251028.

[16] Ghesti G. F., de Macedo J. L., Braga V. S., de Souza A. T., Parente V. C., Figuerêdo E. S., Dias S. C., "Application of Raman spectroscopy to monitor and quantify ethyl esters in soybean oil transesterification," published in Journal of the American Oil Chemists' Society, Volume 83, Issue 7, 2006, pp. 597-601.

[17] Naoko Ellis, Feng Guan, Tim Chen, Conrad Poon, "Monitoring biodiesel production (transesterification) using in situ viscometer," published in Chemical Engineering Journal, Volume 138, 2008, pp.200-206.

[18] De Filippis P., Giavarini C., Scarsella M., Sorrentino M., "Transesterification processes for vegetable oils: a simple control method of methyl ester content," published in Journal of the American Oil Chemists' Society, Volume 72, Issue 11, 1995, pp. 1399-1404.

[19] Falate R., Nike K., Neto C., Caçao Jr E., Muller M., Kalinowski H. J., Fabris J. L., "Alternative technique for biodiesel quality control using an optical fiber long-period grating sensor," published in Química Nova, Volume 30, Issue 7, 2007, pp. 1677-1680.

[20] De Boni L. A. B., Lima da Silva I. N., "Monitoring the transesterification reaction with laser spectroscopy," published in Fuel Processing Technology, Volume 92, Issue 5, 2011, pp. 1001-1006.

[21] William M. Clark, Nicholas J. Medeiros, Donal J. Boyd, Jared R. Snell, "Biodiesel transesterification kinetics monitored by $\mathrm{pH}$ measurement," published in Bioresource Technology, Volume 136, 2013, pp. 771-774.

[22] O. Korostynska, R. Blakey, A. Mason, A. AlShamma'a, "Novel method for vegetable oil type verification based on real-time microwave sensing," published in Sensors and Actuators A, Volume 202, 2013, pp. 211- 216 .

[23] D. Frascari, M. Zuccaro, D. Pinelli, A. Paglianti, "Optimization of mechanical agitation and evaluation of the mass transfer resistance in the oil transesterification reaction for biodiesel production," published in Industrial \& Engineering Chemistry Research, 2009, pp. 7540-7549.

[24] Veera Gnaneswar Gude, Prafulla D. Patil, Georgene Elizabeth Grant, Shuguang Deng, "Sustainable Biodiesel Production," $2^{\text {nd }}$ World Sustainability Forum, November 2012, p. 1-30.

[25] Krishnamurthy Bhat, Bharati Meti, K. Chandrasekhar, "Automation technique for online transesterification process of biodiesel plant in India," published in International Journal of Bio-Technology and Research (IJBTR) Volume 6, Issue 1, Feb 2016, pp. 13-18.

[26] Krishnamurthy Bhat, Bharati Meti, K. Chandrasekhar, "Consolidation of available methods and design of a reliable physicochemical system for transesterification progress monitoring in biodiesel reaction chamber," published in International Research Journal of Engineering and Technology (IRJET), Volume 03, Issue 06, June-2016, pp. $2334-2338$.

[27] Syed F.A. Bukhari, Adesoji A. Adesina, “ Monitoring of Mixing Process by Visualization of Stirred Bio-diesel Production Reactor Uisng Electrical Capacitance Tomography," Proceedings of The World Congress in Computer Science, USA, 2013.

[28] Tri Rachmanto, "Monitoring of Biodiesel Transesterification Process Using Impedance Measurement," Thesis, Doctor of Philosophy, Liverpool John Moores University, 2014.

[29] Cho S., "The in-situ characterization of a transesterification reaction using electrical impedance spectroscopy," Marquette University, 2009.

[30] J. Corach, P. A. Sorichetti, S. D. Romano, "Electrical properties of mixture of fatty acid methyl esters from different vegetable oils," published in International Journal of Hydrogen Energy, Elsevier, Volume 37, 2012, pp. 1473514739 .

[31] Sorichetti P. A., Romano S. D., "Physico-chemical and electrical properties for the production and characterization of biodiesel," published in Physics and Chemistry of Liquids, Taylor and Francis, Volume 43, Issue 1, 2005, pp.37-48.

[32] Romano S. D., Sorichetti P. A., "Dielectric spectroscopy in biodiesel production and characterization," Springer London, 2011.

[33] P. A. Sorichetti, C. L. Matteo, "Low-frequency dielectric measurement of complex fluid using highfrequency coaxial sample cells," published in International Journal of Measurements, Elsevier, Volume 40, 2007, pp. 437-449.

[34] J. Corach, P. A. Sorichetti, S. D. Romano, "Electrical properties of vegetable oils between $20 \mathrm{~Hz}$ and $2 \mathrm{MHz}$," 
published in International Journal of Hydrogen Energy, Elsevier, Volume 39, 2014, pp. 8754-8758.

[35] T. Mariprasath, V. Kirubakaran, "Pongamia Pinnata as Alternate Liquid Dielectrics in Distribution Transformer: A Critical Study on the Property of Viscosity," published in Advances in Energy and Power, Volume 3, Issue 1, 2015, pp. 1-7.

[36] T. Mariprasath, V. Kirubakaran, 'Thermal degradation analysis of Pongamia pinnata oil as alternative liquid dielectric for distribution transformer," published in Sadhana -Journal of Indian Academy of Sciences, Vol. 41, No. 9, September 2016, pp. 933-938.

[37] V. Mamishev, Alexander, Sundara-Rajan, Kishore, Yang, Fumin , Du, Yanqing, Zahn, Markus, "Interdigital sensors and transducers," published in Proceedings of the IEEE, Volume 95, Issue5,2004, pp. 808 - 845.

[38] K. Sundara-Rajan, L. Byrd, A. V. Mamishev, "Moisture content estimation in paper pulp using fringing field impedance spectroscopy," published in IEEE Sensors Journal, Volume 4,Issue 3, 2004, pp. 378-383.

[39] K. Sundara-Rajan, L. Byrd, A. V. Mamishev, "Measuring moisture, fiber, and titanium dioxide in pulp with impedance spectroscopy," published in Tappi Journal, Volume 4, Issue 2, 2005, pp.23-27.

[40] Mohd Syaifudin Abdul Rahman, Subhas Chandra Mukhopadhyay, Paklam Yu, "Novel sensors for food inspection modeling fabrication and experimentation," published in Measurement and Instrumentation, Chapter 2, 2014, pp. 11-35.

[41] Tsamis E. D., Avaritsiotis J. N., "Design of planar capacitive type sensor for water content monitoring in a production line," published in Sensors and Actuators A, Volume 118, Issue 2, 2005, pp.202-211.

[42] Mukhopadhyay S. C., Gooneratne C. P., "A novel planar-type biosensor for noninvasive meat inspection," published in IEEE Sensors Journal, Volume 7, Issue 9, 2007, pp. 1340-1346.

[43] Subhas Chandra Mukhopadhyay, Tarikul Islam, "Wearable Sensors- Applications, design and implementation," published as Chapter 1, IOP Publishing, 2017, pp.1-31.

[44] Blakey R., Korostynska O., Mason A., Al-Shamma’a A., "Real-time microwave based sensing method for vegetable oil type verification," published in Procedia Engineering, Volume 47, 2012, pp. 623-626.

[45] Korostynska O., Mason A., Al-Shamma'a A. I., "Flexible microwave sensors for real-time analysis of water contaminants," published in Journal of Electromagnetic Waves and Applications, Volume 27, Issue 16, 2013, pp. 2075-2089.
[46] Deibnasser C. Campos, Evandro L. Dall'Oglio, Paulo T. de Sousa Jr., Leonardo G. Vasconcelos, Carlos Alberto Kuhnen, "Investigation of dielectric properties of the reaction mixture during the acid-catalyzed transesterification of Brazil nut oil for biodiesel production," published in Fuel, Volume 117, 2014, pp. 957-965.

[47] Rui Igreja, C.J. Dias, "Analytical evaluation of the inter-digital electrodes capacitance for a multi-layered structure," published in Sensors and Actuators A, Volume 112, 2004, pp. 291-301. 